\title{
A Review of Agile Internal Auditing: Retrospective and Prospective
}

\author{
Prem Lal Joshi \\ Senior Fellow, ICSSR, Western Regional Centre, India \\ prem@acadjoshi.com,alp74297@gmail.com
}

\begin{abstract}
Today, audit stakeholders are demanding speedy information on audit assurance, compliance, advisory practices, the anticipation of risks, and effective controls for decision making and to monitor agents with minimum efforts. They want that internal audit function to contribute greater value to the business. Failure to demonstrate how internal audit function adds value will eventually result in stakeholders viewing internal audit as irrelevant. Therefore, this article reviews the agile internal auditing from a retrospective and prospective angle and provides some insights into the concept, history, need, methodology, characteristics, implementation process, advantages, and challenges with the help of a literature review. The article focuses more on Agile methodology as applied by internal auditors to provide speedy information. The agile approach is particularly, appropriate for complex audits which require a focused team coupled with experienced auditors to follow shorter audit cycles and faster delivery of services to its clients. Since, the agile internal audit function's agility will vary widely from one company to another, due to the size and organizational culture, the article concludes that academics, researchers, and practitioners need to provide deeper insights into this emerging approach by conducting empirical, theoretical, and practical studies on its applications, challenges, success and failure stories. Also, agile internal audit case studies to generate hypotheses based on cross-case analyses need to be conducted. It also suggests some of the future directions for research in this emerging area.
\end{abstract}

Keywords: Agile internal audit, Scrums, Characteristics, Traditional waterfall audit, Kanban, Audit sprints, Audit backlog, Challenges, Benefits, Iterative reporting, Mindset

\section{Introduction}

The internal and external audit environment has been undergoing tremendous changes due to ongoing digital disruptions and an increased number of financial scandals and frauds. The traditional waterfall and labor-intensive internal auditing are being automated [1]. The Chief Internal Auditors (CIAs) are facing higher expectations from the Board and management. PWC [2] in a report inferred that only $44 \%$ of internal stakeholders believe that the internal audit function is adding significant value. Therefore, there exists a gap between internal audit performance and stakeholder expectations. Additionally, stakeholders strongly believe that internal auditors have to be more trusted business advisors. In the world of economic volatility, traditional internal auditors have failed to address disruption-related risks [3]. Audit researchers posit that the auditing needs to adopt a reactive audit planning approach to one that is more agile. Agile is an approach to re-think the way teams go about completing tasks

Article history:

Received (April 27, 2021), Review Result (May 30, 2021), Accepted (August 4, 2021)

Print ISSN: 2288-8969, eISSN: 2207-516X IJSBT

Copyright (C) 2021 Global Vision Press (GV Press) 
or larger initiatives. Agility involves a quicker adaption to the external and internal environments which can result in improved operating performance, quality, and client satisfaction [3].

Therefore, the focus of this paper is to provide some insights into the adoption of agile internal auditing. Section-2 provides history, concept, features, and need for agile auditing. Section- 3 differentiates between traditional waterfall and agile internal auditing. While section 4, explains scrum and Kanban methodologies and their various components and processes. Section-5 contains a description of implementation and maturity levels. Section-6 contains the literature review of the findings from surveys and case studies. This section also describes the benefits claimed from the adoption of the agile approach. Challenges to internal auditing are also explained. Lastly, section-7 includes conclusions and some possible areas for future research.

\section{Agile internal auditing}

\subsection{History of agile auditing}

In recent years, agile transformation has become popular among internal audit functions. Therefore, it will be of interest to track its origin and development. The literature indicates that agile originated in software development. This practice was first codified as an efficient, iterative process of software development. The Manifesto for Agile Software Development was started by 17 software thinkers at a Utah ski resort in the USA in February 2001. Its methodology was developed first in 2001 by a group, who observed that the software industry was not adapting quickly in response to market and technology transformation. There were big-time gaps in product development and delivery to the customers. Agile on the other hand, addresses this issue as a challenge and through innovative ideas and strategies that are tied to risks, costs, and feedback for an iterative approach to software development. The highest priority is customer satisfaction [4].

\subsection{What is agile auditing?}

The word agile means "the ability to move quickly and easily" or moving intelligently quickly. Agile applications in internal auditing strive to elevate the performance and value of internal audits. This is achieved through team collaboration to deliver services and advice promptly. Deloitte [5] defines it as "Agile Internal Audit is the mind-set of Internal Audit function will adapt to focus on stakeholder needs, accelerate audit cycles, drive timely insights, reduce wasted effort, and generate less documentation". While, Wright [6] states that it is an innovative approach that applies software development values, principles, and practices to improve IA engagements. Agile IA aims at changing audit focus and updating its scope.

Since agile provides a greater degree of transparency and visibility to move ahead, therefore, it demands greater discipline than traditional internal auditing approaches. Agile is the ability to create and respond to changes in clients' and stakeholders' expectations. It is a way of dealing with, and ultimately succeeding in an uncertain and turbulent environment. This is achieved through team collaboration to deliver services and advice on time. According to Berger [7] "Agile auditing provides an alternative to the traditional and sequential "waterfall" audit process: not changing what we do but how we do it. The agile approach to audit is more flexible, responsive to changes, and based on transparent communication and engagement with business stakeholders". 
Thus, agile auditing uses agile software development values, principles, frameworks, methods, and practices in the execution of internal audit engagements [8].

\subsection{Features of agile internal auditing}

The following [Figure 1] portrays some of the key characteristics or features of agile internal auditing.

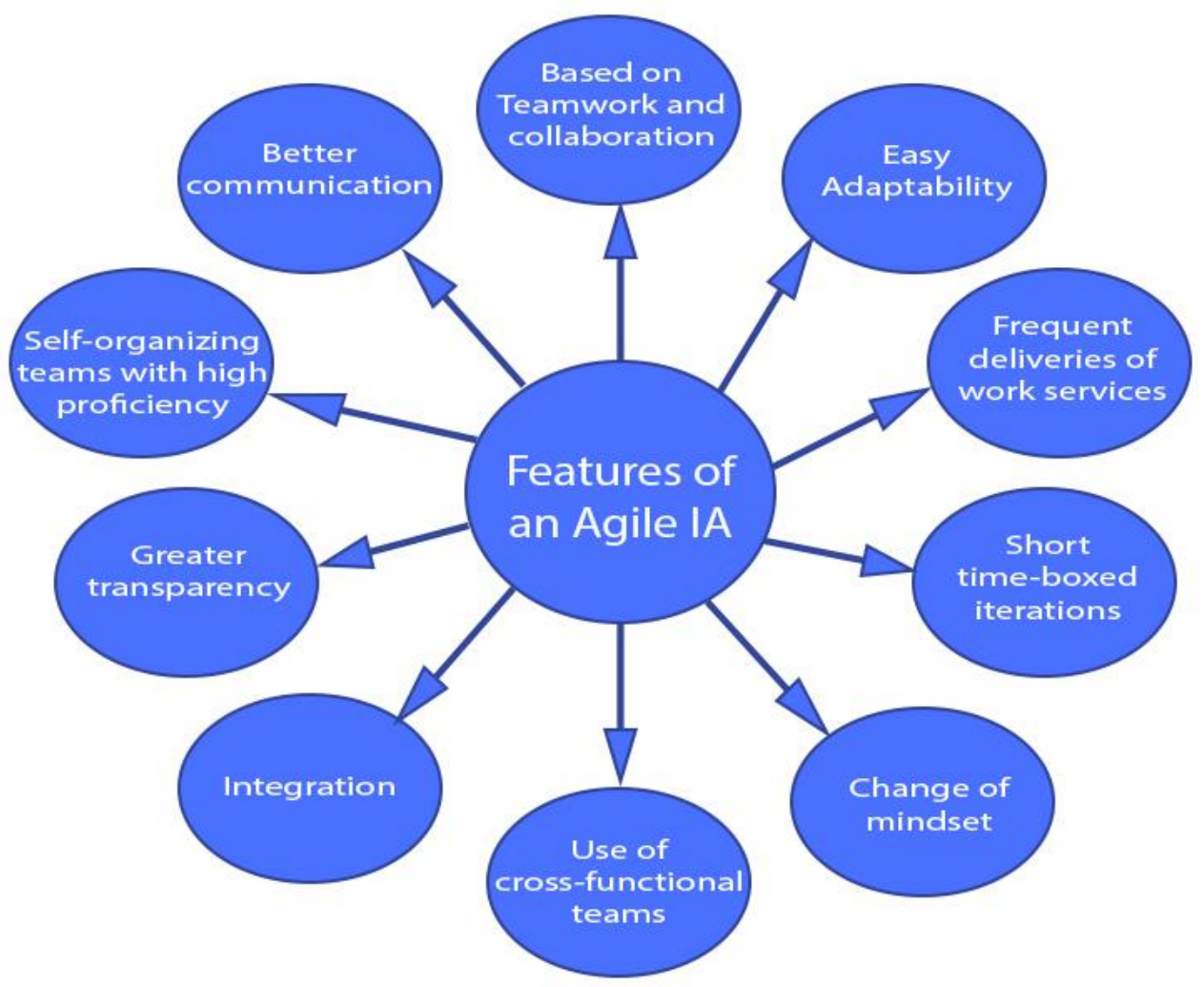

Figure 1. Features of an agile internal auditing

There are ten characteristics shown in [Figure 1] of an agile internal auditing approach which is briefly described below:

(1) There is a focus on collaboration and cooperation in this approach. Based on quick feedback between developers and clients, the project stays on track.

(2) Clients are directly involved in the audit process and they observe the continuous development in the project, the agile approach enables a greater level of transparency [9].

(3) Communication process is enhanced in an agile approach because it may embrace the latest communication technology and communication is face-to-face. Deloitte [10] states that "The agile environment encourages developers to partially completed work to the product owner and other stakeholders as a sprint progress".

(4) One of the characteristics of an agile approach is its ability to shorten the time between planning and product delivery. 
(5) There is more flexibility to change when change is needed and the focus is on developing the right product.

(6) Another characteristic of the agile approach is that the team can deliver high-value product features in a short period [11].

(7) One feature of the agile approach is that meetings are held within the audit teams who assess whether the execution and performance are proceeding according to planning and any bottlenecks are being faced by the team.

(8) Agile approach uses a cross-functional team who are from different functional expertise and operate to achieve a common goal. Each member plays multiple roles and provides ongoing support and maintenance.

(9) The integration of agile methods may assist in adding the value of the internal audit function and the internal control in the organizations [12]. The system may be integrated with other risk and compliance applications.

(10) Change of mindset is generally a factor for successful implementation of agile internal auditing. It is assumed that the whole firm will follow agility [13]. It implies that IAF is expected to focus on stakeholder needs, reduce waste and improve audit cycles as well.

\subsection{Why agile internal auditing is needed?}

In many industries, disruptions are bigger, coming faster, and require quick and out-of-thebox responses. In this environment, agile auditing can help some organizations adapt and become more flexible. The Chief Audit Executives (CAEs) need to lead the response to disruption with innovative strategies and an equally flexible approach supported by the right talent [14]. The bottom line is that the internal auditors need to be more agile. In this regard, Romano [14] states "Evaluating emerging technologies, analyzing opportunities, assessing quality, efficiency, and providing accurate and timely communication represent a fraction of how internal auditors engage daily. This comprehensive scope of responsibilities provides internal auditors with a broad perspective throughout an organization".

Certain practitioners argue that the internal audit function is losing the perception of a "value add" in this fast-changing world [15]. Internal audit teams can't predict market disruptions, last-minute regulatory changes, and unexpected cybersecurity or data privacy threats. So how can these departments operate in today's dynamic business environments while continuing to provide timely assurance and valuable insights? They need greater flexibility in their functioning. Galvanize [16] points out that to add significant organizational value and to be a trusted strategic business partner, internal audit needs to evolve, and agile techniques can help. Therefore, agile auditing can look to provide deeper insights, assessing responsive risk threats, improving that risk, and more timely and impactful reporting. Deloitte [17] states that agile is needed in internal auditing for better, faster, happier results.

Additionally, Lehmann et al. [18] point out that terms of speed and changing nature of internal auditing require the internal auditors to reduce their focus on the manual testing of risks and controls and increase the focus on key and strategic risks. They further suggest that more advanced data visualization techniques are needed for continuous risk assessment.

\section{Traditional waterfall auditing and agile internal auditing}

In the traditional waterfall approach, product development undergoes analysis, design, implementation, and testing phases. This is considered an expensive approach because the 
time and effort are spent early on in the design and analysis phases. There could be resistance to change because the team resources are invested in the requirements before the project begins, for example, developing a customer address book.

On the other hand, in an Agile approach, the product manager usually creates on a priority basis the documents requirements (e.g., new contacts for a customer book). Then timeframe is followed for iterations (1,2 or 3) in which design, development, and testing for these items (e.g., new contacts) may be performed. Finally, the product functionality may be released. In this approach, product change (risk management) is considered inevitable. It also uses a crossfunctional team. Thus, in this way, an agile approach uses an iterative and incremental method and it tries to derive benefits from both to develop products that better meet customers' needs.

Alexiou [19] provides two real-world examples in his article. They include an audit involved checking billing records produced by Information System (IS) devices and second, a penetration test on company systems by an IS auditor. Under the traditional waterfall system, the processes were too complicated and time-consuming. By applying the agile approach, the auditors were able to solve the problems in less time with good results.

\subsection{Differences between traditional auditing and agile auditing}

The following [Table 1] describes the main differences between traditional waterfall internal auditing and agile internal auditing.

Table 1. Differences between traditional auditing and agile auditing

\begin{tabular}{|c|c|}
\hline Traditional Auditing & Agile Auditing \\
\hline $\begin{array}{c}\text { It involves a rigid and single-phase planning of } \\
\text { audit work. }\end{array}$ & $\begin{array}{c}\text { It involves a process that is based on flexible, } \\
\text { iterative planning on an ongoing basis in "sprints" } \\
\text { (short bursts of planning, work, and increased } \\
\text { collaboration) }\end{array}$ \\
\hline $\begin{array}{c}\text { Often communication among the team members } \\
\text { and stakeholders breaks. }\end{array}$ & $\begin{array}{c}\text { It focuses on continuous communication and } \\
\text { collaboration, both among the audit team and with } \\
\text { stakeholders. }\end{array}$ \\
\hline $\begin{array}{c}\text { The planning, fieldwork, review, and reporting } \\
\text { stages may take up to eight weeks or more. }\end{array}$ & $\begin{array}{c}\text { These three phases are completed in much shorter } \\
\text { time frames. }\end{array}$ \\
\hline Audit planning & Backlogs \\
\hline Fieldwork \& Review & Sprints and retrospectives \\
\hline End of Project Reporting & Iterative reporting \\
\hline Focuses on detailed documentations & Responding to change [20] \\
\hline Adhering to plan & \begin{tabular}{c} 
Roftwased auditing \\
\hline
\end{tabular} \\
\hline
\end{tabular}

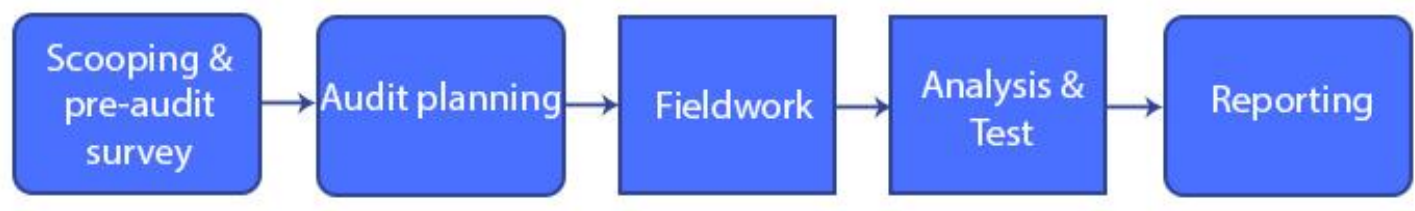

Figure 2. Processes in traditional waterfall internal auditing

The traditional waterfall internal auditing follows a typical process as depicted in [Figure 2]

It has large-scale projects; outputs are reported at the end of the audit cycle and internal auditors strictly adhere to the established processes. It lacks flexibility. 
On the other hand, in an agile methodology for internal auditing, DBTI (design, build, test/check implement) with short duration is followed. agile is a learning and adapting each time, adding value with each iteration.

\subsection{Processes in the agile approach}

The following [Figures 3] and [Figure 4] respectively show the processes in an agile approach:

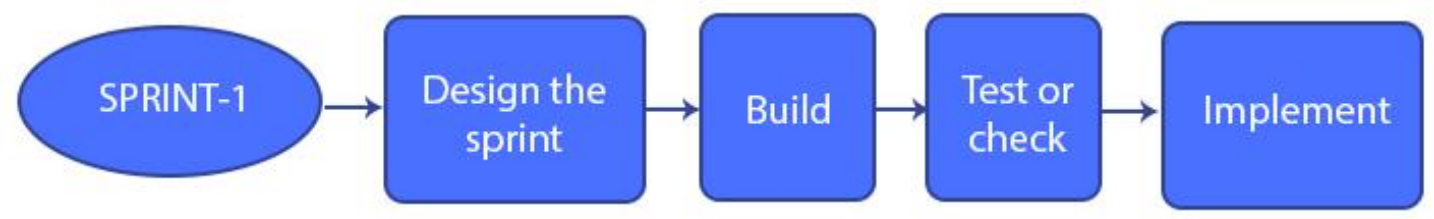

Figure 3. Processes in an agile approach

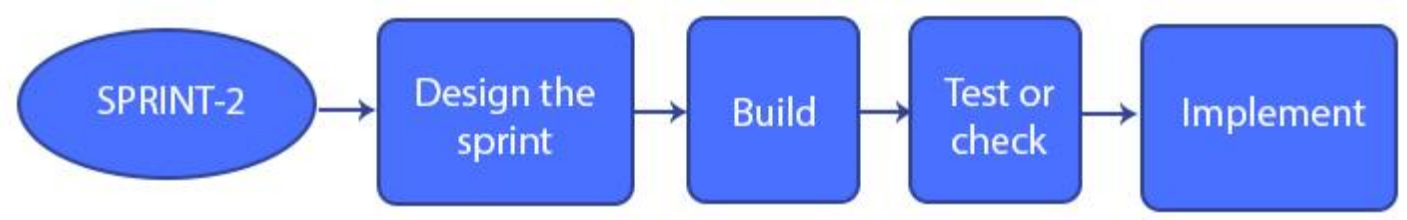

Figure 4. Processes in an agile approach

Source: Adopted: Blanding and Child [21].

Auditing.https://chapters.theiia.org/topeka/Documents/Agile\%20Auditing\%20Topeka\%20IIA\%20100119.pdf

Agile auditing is designed to be flexible and uses multiple iterations. All sprints are iterations, but not all iterations are sprints. Audits are divided into sprints which are timeboxed intervals in which tasks must be completed. Sprints provide a process, structure, and cadence for the work [5]. In this approach, there are smaller increments of work, continual feedback, and work improving the audit processes.

\section{Methodology}

Agile is an approach that involves multiple project management methodologies. No stereotype methodology may be selected by the audit team rather various methodologies are used in agile as the choice depends on the unique needs of the business and its objectives. The agile methodology gives audit teams more opportunities to prioritize and deprioritize risks and add or remove audit works based on the insights they gain from more frequent testing and review [22].

There are generally three basic core or structural components to agile auditing which are: Backlog (collection of scoped work like audit plan), Sprints (scoped items divided into sprintstime period), and Scrums (short and concise meetings to evaluate the work done and identify bottlenecks) [7]. The supplementary parts in an agile audit include cross-functional teams, continuous integration, and an information Dashboard. The following [Figure 5] depicts a general methodology. 


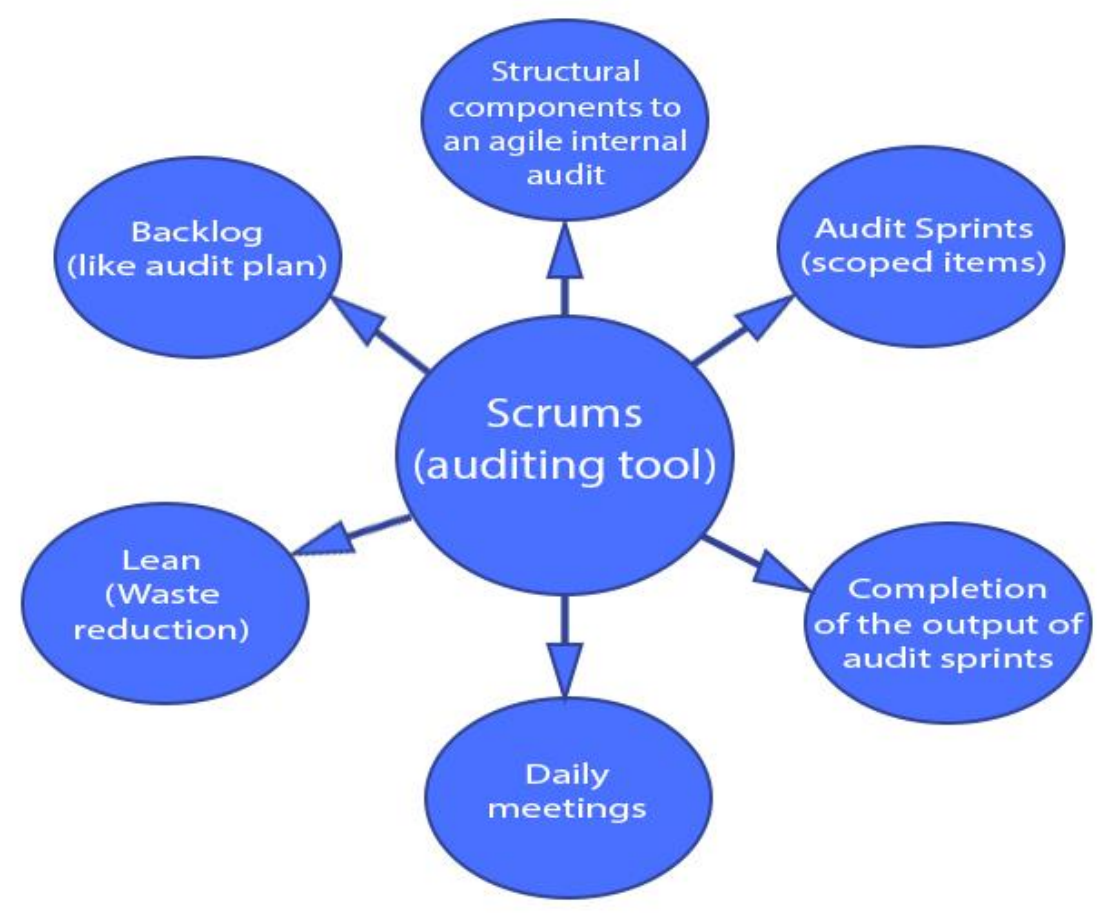

Figure 5. Structural components of an agile internal audit

\subsection{Scrum}

The available literature [23] shows that the most fundamental agile framework that has been applied to IA work processes is Scrum methodology. According to the dataset of Organize Agile Scrum is the most popular agile methodology, with $80 \%$ of respondents stating that they use the approach within their agile transformations [24]. Scrum is focused on efficiency and quality.

This methodology involves the participation of small cross-functional audit teams who work on audit projects in short periods. It is an agile auditing tool. Wilhelm [23] states that "Scrum is, in short, is a set of rules which organizes work processes in loops of improving trials and errors (so-called Sprints), running in largely self-organized teams with daily transparent progress updates (Daily Scrum)".

This scrum board helps to visualize where the audit team is, where they are going, obstacles faced, and other practical applications within internal audit. In other words, scrum includes fixedschedule stand-up meetings in which the team reviews projects' progress or lack thereof. The scrum team is usually self-governing and the team members themselves decide on the tasks to be completed within each sprint. It is being a flexible approach, progress of the audit work is tracked based on backlog, work to be done, work in progress, and done tasks. The audit team determines and plans the audit activities and deliverables on which each sprint will focus.

\subsection{Lean}

Another core part of agile IA is lean. It is termed as a management concept or philosophy which aims to derive the highest value for the clients with the least waste of resources. 


\subsection{Audit sprints}

Iterations are one of the basic building blocks of agile development [25]. It is an important part of the agile methodology. The concept is to understand in terms of the item that is unlisted from the backlog during execution and the various scope elements are split into definable auditable subjects. These auditable subjects are called sprints. These sprints are nothing but short periods during which an element has to be completed, say, 1 to 2 weeks. An agile approach helps the internal auditor speed the work. Hence, sprints provide a process, structure, and rhythm for the internal auditor's audit work [26].

\subsection{Audit backlog}

The audit backlog includes the items that are abstract on the scope, the process as well as timing. The internal audit department has to keep a backlog of audit work or areas which are to be regularly reviewed and evaluated based on risk exposure.

When the internal audit function and its stakeholders (represented by directors and the audit committee) revise their audit needs, such audit items generally will have higher priorities on the backlog till they are ready for audit work.

Additionally, in creating a backlog, it should also undergo backlog refinement because there may be requirements that were a bit EPIC and the doer might be confused with the requirements, therefore, the value that was initially expected may be difficult to meet. The backlog may also undergo backlog refinement to create value.

\subsection{Completion of the output of audit sprints}

This element describes the output completed of the audit sprints. It may also include observations, risks confronted, and recommendations. In other words, it helps in highlighting the point when a sprint has been completed.

\subsection{Daily meeting}

It is to be recalled here that sprints (iterations) begin with scheduling meetings. Here, the team members agree on what work will be completed within the sprint. This is followed by short, daily "stand-up" meetings, where team members discuss their work about what has been achieved and what they will do today. This is to ensure that the project work can be successfully delivered. It involves the everyday meeting of the audit team for a short time to coordinate the work and audit plan for the next day. In a daily meeting, the audit team also reviews the work completed and the problems encountered by them during the audit process, and how to remove them. In this context, KPMG [12] states that "It is to be noted that of the audit sprint is always kept in mind during the stand-up. This stand-up makes it more likely that the goal of the audit sprint will be achieved".

\subsection{Sprints retrospective}

It is common in agile audit to organize a retrospective at the end of each sprint. A meeting between the internal audit team and stakeholders is held to review the work, receive feedback, and analyze the results of the sprint [27]. The purpose is to discuss issues and obstacles faced in the audit process by the team members and they try to solve them where it may be possible. $t$ is imperative that an open environment for the team is created for a frank discussion of waste and its consequences. KPMG [12] argues that in every team, there is a scrum master 
(specialist) who manages the processes in the right direction and manages the role resistance. Beerbaum [13] states that "Culture of immediate feedback daily retrospective enables early addressing of issues".

It is to be stated that for the sprint to be successful, the Daily Stand-up meeting, the Sprint Review Meeting, the Demo to the product owner, and the sprint retrospective meeting, etc. may ensure its success. Since these meetings involve collaborative discussions and reviews, the team may ensure that the product is progressing as planned. Additionally, as the product functionality is split into smaller features (EPICS and stories) by-product owners, these stories may be prioritized and taken up in each sprint or iteration. Therefore, the story point being consolidated from sprint planning to judge its success.

\subsection{Another methodology}

It is considered similar in approach to Scrum which tracks work to be done, work in progress, and work done. Kanban is a Japanese word that means visual signal or card. It is a Japanese manufacturing system. Kanban looks at communication, collaboration, and accountability aspects in an agile approach.

There are four fundamental Kanban principles as presented in [Figure 6] as follow:

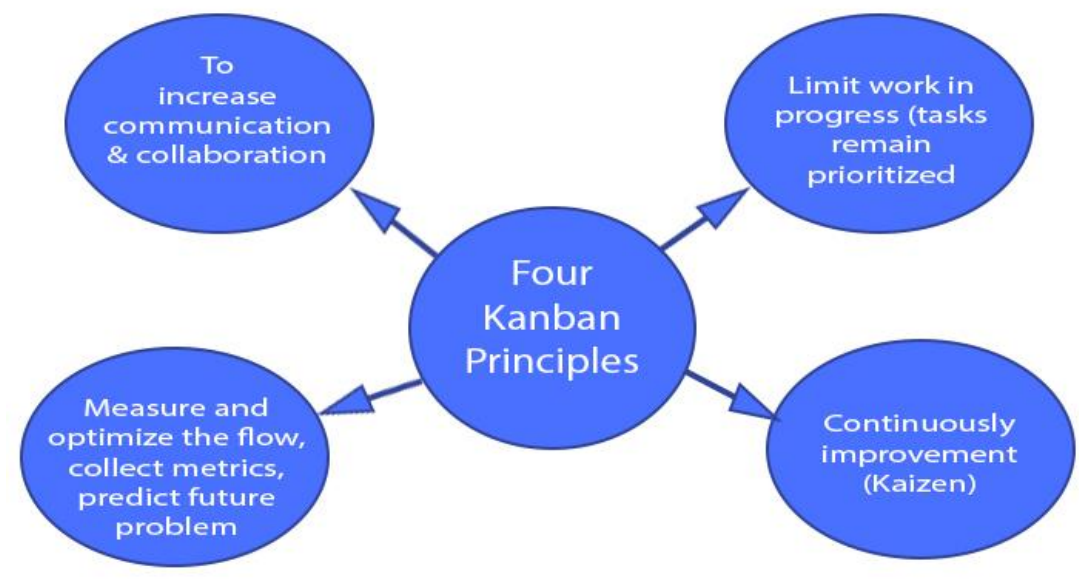

Figure 6. Kanban principles

Kanban information board contains bottlenecks, progress, blockers, process inefficiencies, and impediments. This information enables to reduce of value-less activities, collects appropriate metrics to measure performance. The predictions are generally based on more reliable latest real data rather than the project manager's guess [28].

Work in Progress (WIP) limits balances the number of work items in the different stages of the workflow. Implementing WIP limits helps to complete single work items faster. The team gets an opportunity to locate bottlenecks in their WIP.

Kanban encourages constant improvement and team members work collaboratively to find the right solutions for process improvement. There is continuous communication among the team members.

Kanban focuses on monitoring and analyzing the work done to look for the next best way to improve it. Since resources and customers' needs keep changing, the team assesses the flow of work continuously. 


\section{Implementation considerations}

According to Eleanor Taylor, a senior manager at Nationwide Building Society, UK [4], the implementation advice when introducing Agile in internal auditing is depicted in [Figure 7].

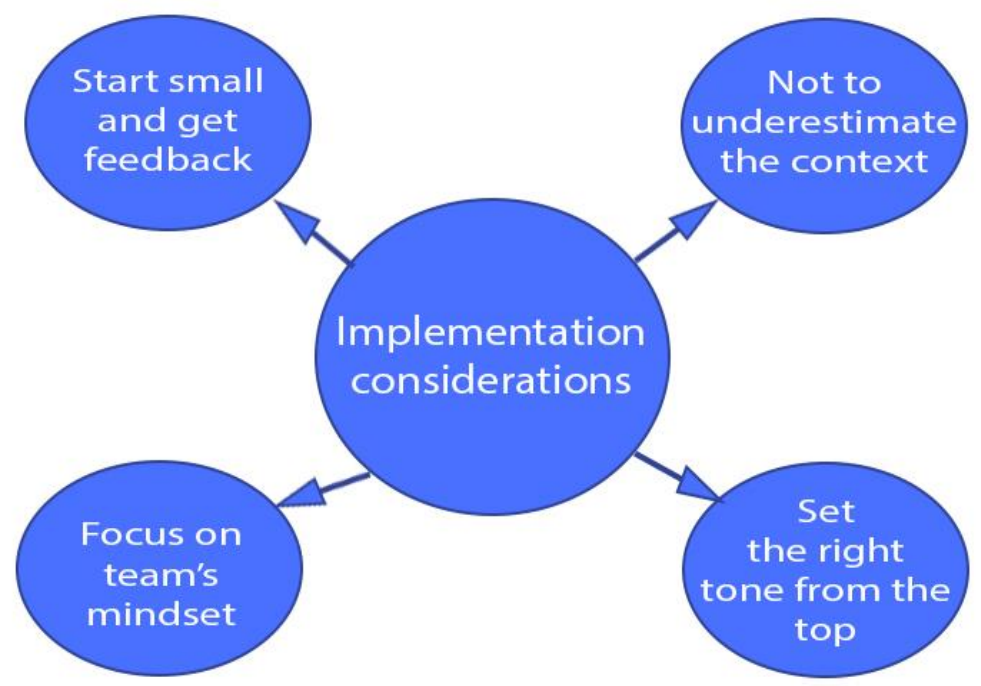

Figure 7. Implementation consideration

[Figure 7] portrays four key important considerations in the implementation of agile internal auditing. Working in a small team continuously receiving feedback on the audit work being performed, not to underestimate the context of the audit processes, focusing on changing the mind-sets of the audit team, they should be innovative and idea generation, and setting the right tone at the top management level is necessary for the successful implementation of an Agile methodology.

Similarly, [Figure 8] shows that the support elements in the process should be the inclusion of cross-functional teams, information dashboard and continuous integration of the audit elements are some of the supporting elements in the effective applications of agile internal auditing.

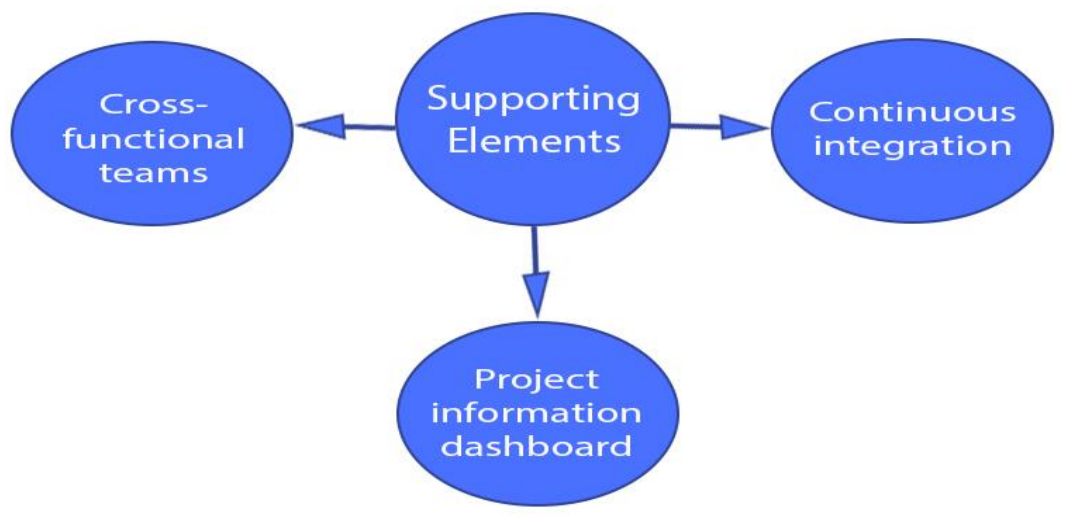

Figure 8. Supporting elements to effectively apply agile to an internal audit 
On the implementation of agile internal auditing, Deloitte [29] states "Because internal audit groups vary widely in their capabilities, resources, and readiness for change, the successful adoption of Agile IA depends heavily on leadership within the function, the audit committee, and senior executives". Furthermore, the agile internal audit ultimately is the mindset and method in which the internal auditor has to focus on the needs of stakeholders. It accelerates the audit cycles and reduces the waste of resources. Not only this but also, an agile method enables auditors to achieve higher productivity and added value. Thus, the lead time in the audit can be reduced.

\subsection{Maturity levels}

Agile internal audit has various maturity levels in the completion of an audit. There are generally five such maturity levels which are presented in [Figure 9] as below:

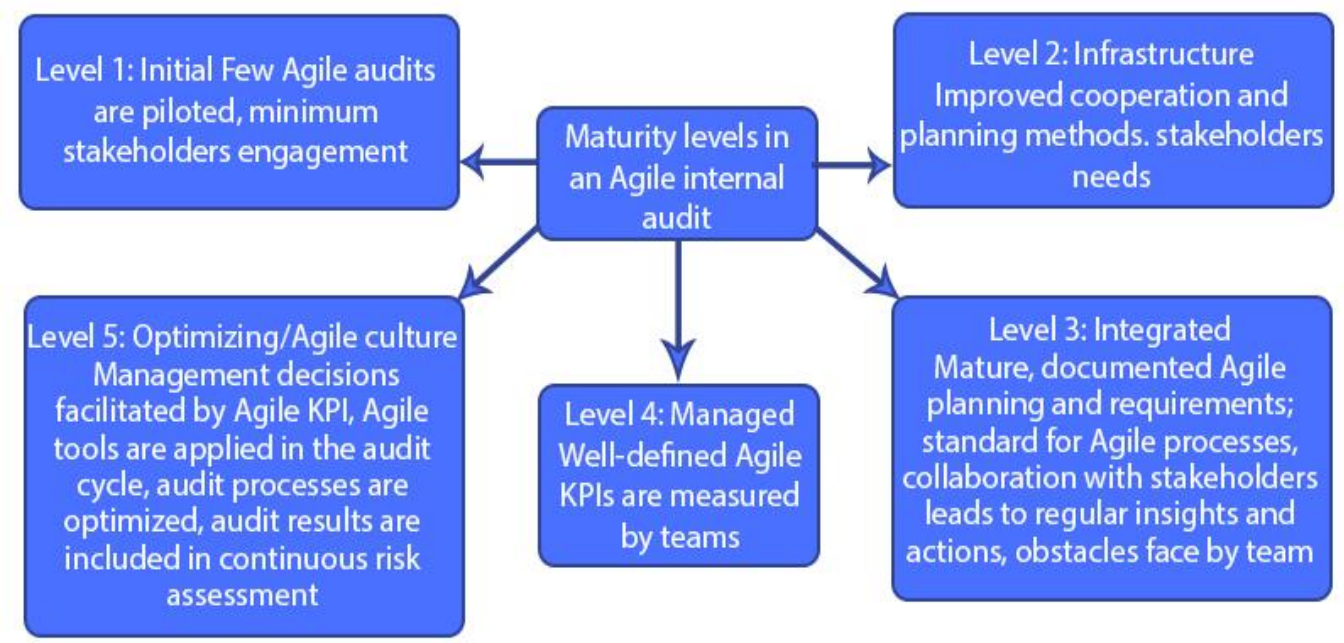

Figure 9. Maturity levels of agile internal audit

Source: Agile Internal Audit, KPMG [12]. https://assets.kpmg/content/dam/kpmg/sg/pdf/2019/09/agile-internal-audit.pdf

A perusal of [Figure 9] indicates that there are five maturity levels in an Agile internal auditing approach. At the initial level, Agile audits are piloted and stakeholders are minimally engaged. At level two of maturity is the development of infrastructure in terms of improving team cooperation and planning methods for audit work to be performed. While at maturity level three, an integration towards the following standard for Agile processes, and collaboration with stakeholders are done. Well-defined KPIs (metrics) are measured by teams at level four and at maturity level five, Agile audit tools are applied in the audit process and audit processes are optimized. A continuous assessment of risk is also performed.

Agile minds might have developed several KPIs (metrics) to measure the success of the project. However, Connors [30] suggests four critical and practical KPIs (metrics) which are: cycle time (productivity), escaped defect rate (quality), planned-to-done ratio (predictability), and happiness (stability). Connors [30] further states that while cycle time and escaped defect rate, can be easily quantified, planned-to-done may result in an immediate real effect and may be useful in forecasting. The overall health of the team may be measured through the happiness metric. 


\section{Literature review: Surveys and case studies}

\subsection{Surveys and case studies}

Global companies that have adopted Agile auditing practices include Apple, IBM, Microsoft, Proctor \& Gamble, Suncorp, etc. Spencer and Wang [31] in a case study of Suncorp, an insurance and banking company, report that the internal audit department helped Suncorp's Board, and management in accomplishing its objectives by independently reviewing and reporting on the effectiveness of risk management, controls, and governance processes by implementing an Agile approach to internal auditing. The company was facing the problem to deliver on a large portfolio of complex audits, within a dynamic environment. The outcome of this Agile approach is described below:

(1) "Overall, the transition to Agile has transformed the way that internal audit operates, and made delivery of audit work more transparent and efficient. It has also made what can be traditionally a heavily, structured process, more fun - encouraging open communication and personal interaction".

(2) Through a case study, Gartner [32] reports that audit leaders at Aflac updated their staffing, planning, and project management approaches based on Agile principles. The audit department used the new methods to increase department efficiency and covered more risk areas with the same resources.

(3) Similarly, Mkoba and Marnewick's [33] study research reveals that there was a significant correlation between the identified audit processes and Agile project success. This research emphasizes the need to take into account auditing agile projects from initiation to closure.

(4) Newmark et al. [3] state that the inspect-and-adapt philosophy inherent in Scrum enables audit teams to effectively work in ever-changing conditions, resulting in a high level of sustainable productivity.

(5) KPMG [26] in a case study, reports that the internal audit function of a global bank has implemented several key Agile principles and instruments in the daily performance and execution of audits. Daily stand-up meetings were organized within the audit teams to assess whether the execution and performance is in line with planning. The bank identified bottlenecks, and whether the right prioritization was given.

(6) The study finding of Beerbaum [13] reveals that daily meetings with the Agile team assist in enhancing the independence of the internal auditor.

The following descriptions are related to the benefits which are claimed in the literature from the adoption of an Agile approach in internal auditing.

\subsection{Flexible approach}

An Agile approach uses a flexible methodology for the specific needs of an internal audit function and its stakeholders. Its purpose is to reduce waste, costs, and time for delivery to the customers. The agile methodology includes delivering tested products in short iterations. In this regard, Hogan [34] argues that scoping flexibility can be enhanced through better information sharing and inputs provided by the scrum team. Galvanize [16] states 
"An agile approach can reduce audit costs and save time, while also improving overall audit quality. It increases communication, iterative planning, and there is more empowerment in individual roles".

Case study research by Wilhelm [23] reveals that already fast-paced and innovative audit teams, the implementation of Scrum is enhanced by the internal audit team's collaborative involvement which strengthens knowledge sharing and Agility in return.

\subsection{Enhanced internal audit planning and communication}

Being flexible and iterative, there is a continuous updating of the backlog of audits works and projects, which are performed on a priority basis, ranked on risks, and as well on company needs. Communication is more frequent and informal, and reporting is more common through ongoing dashboards and updates, rather than formal full audit reports. Deloitte [5] states that there is continuous communication with all stakeholders. Additionally, audit teams become more responsive and do not adhere to much longer and more resource-intensive plans like in the case of the traditional waterfall audit approach.

\subsection{The response rate is faster}

Agile internal auditing delivers a quick response to emerging needs and requirements of the company [5]. It also maintains better and more transparency tracking the progress of audit work because there is frequent communication during the audit process. Agile internal audit helps teams to transform to deliver on multiple criteria like assurance, advising, and anticipating risks [20].

\subsection{Less and relevant documentation}

An agile internal audit involves only relevant and less documentation. This enables the internal audit to report on a timely basis to the audit committee and the management. According to Alexiou [19], "In agile models, design and specification documentation are kept to the bare minimum required, and the major part of the documentation is created at the operations and support levels".

\subsection{Increased value and risk-specific insights}

By streamlining the work and documentation, agile helps focus internal audit's attention on the insights, risks, and opportunities that stakeholders need [16]. It also allows the internal audit to be more adaptive and helps the team deliver the value that the clients demand. Additionally, working in sprints, internal auditors check the progress of their work in short time intervals, and they do not have to wait until the end of the work completion cycle. Through this process planning, fieldwork, and review work are delivered more quickly.

In addition, to the above benefits expected, there are some possible challenges that internal auditing may face from agile adoption. [Figure 7] depicts some of them.

\subsection{Challenges to agile internal auditing}

An Agile IA can probably deliver innovative products and services, but there are also challenges in its implementation and operation. Some of them are presented in [Figure 10]. 


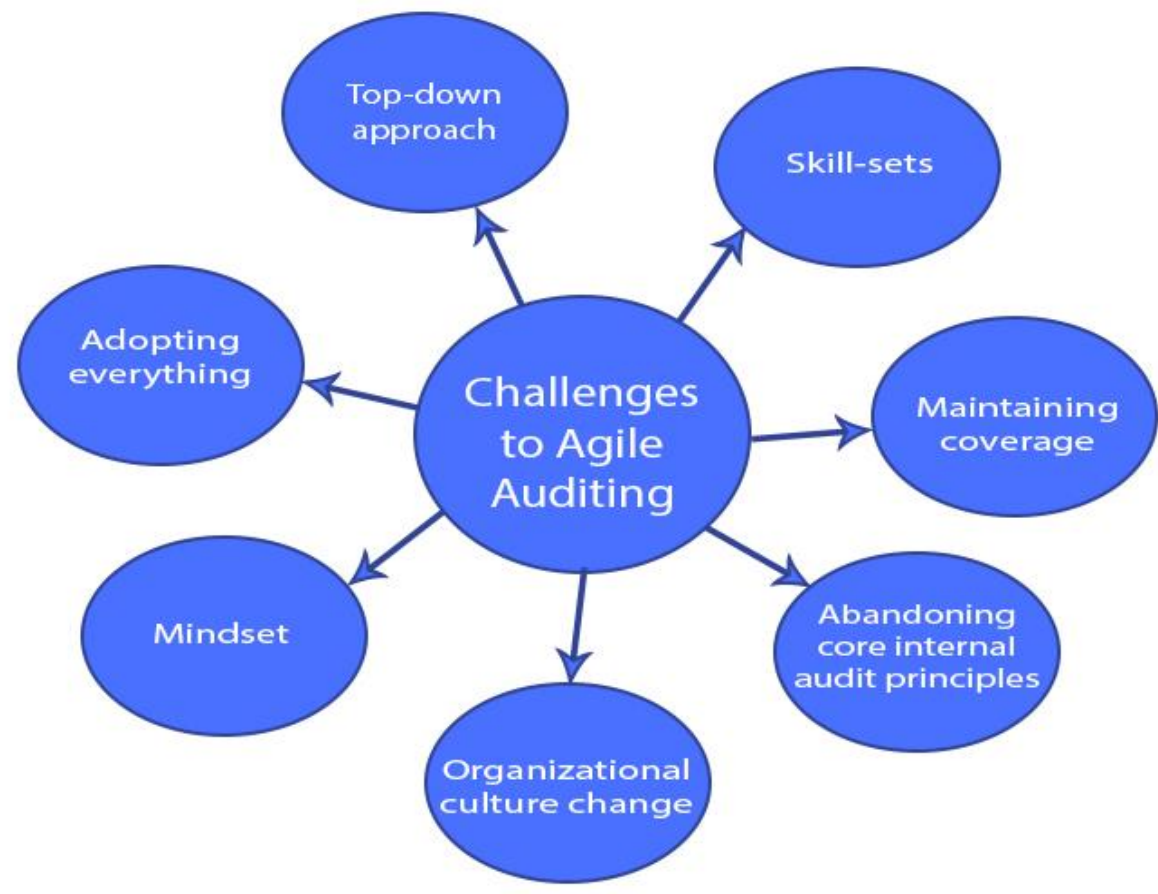

Figure 10. Challenges to agile internal auditing

Source: Adopted from Berger [7] (https://blog.protiviti.com/2020/01/27/agile-internal-audit-how-to-audit-at-the-speed-of-risk/)

In an agile environment, the internal audit function has to respond effectively and promptly [10] to the environmental changes. Changing the mindset of auditors is not very easy because traditionally they are used to strictly adhere to rule books. During crisis times like COVID19, changing their mindset may not be that easy. However, an effective training and coaching strategy may be required for getting the mindset right for teams to be high-performing and result-oriented. The organization needs to create a conducive work environment so that the teams get motivated to work in such environments and learn how to cultivate and prune. In a team culture, members should be comfortable expressing their opinion extend their support for collaboration, and potential ability to change. In this regard, McIntosh [35] proposes the following "An Agile mindset is the set of attitudes supporting an Agile working environment. These include respect, collaboration, improvement and learning cycles, pride in ownership, focus on delivering value, and the ability to adapt to change. This mindset is necessary to cultivate high-performing teams, who in turn deliver amazing value for their customers".

The agile approach requires cross-functional teams with all the skill-sets to deliver the sprint and product requirements. It may also be a challenge how to optimally form a team because the skill sets of the team members may also differ. There could be some confusion over the overlapping of team members' roles. Further, the agile audit is not a substitute for risk identification and rational planning [19].

Compliance with regularity requirements and internal audit standards are still to be met when the agile approach is adopted. However, how this may be adopted without abandoning or compromising with core internal auditing principles. 
The top-down approach has its limitations. Instructions to change generally originate from the top, often lacking clear guidance for change. The change of organizational culture takes a longer time. People suspect quick changes.

Berger [7] argues that improving transparency and tracking coverage decisions are essential in an agile approach. How to ensure that this may not reduce the risk coverage or documentation? Team members have to rethink coverage approaches which may create stress problems too.

\subsection{Organizational capability and culture}

The successful implementation of the Agile approach to internal auditing will also depend on firm size, capability, and cultural values they promote among their employees. As there is more interaction between the audit team and the auditee which improves the management expectations, therefore, a culture of cooperation needs to be built among the various departments. Sarah Adam of Deloitte [29] in an interview to CFO journal states "To facilitate workflow management, two steps are useful. The first is to define the Agile IA manifesto. Each IA group is different and functions in a unique culture, so it is necessary to modify the agile IA manifesto so that it works for a given organization".

\section{Conclusions and implications}

The internal audit function is considered a financial watchdog for any company. The internal audit's task is to focus on enterprise risk management functions, security processes, and regulatory compliance, among other things. When the organization is exposed to new and significant risks, an internal audit needs to be able to update its plan ad provide assurance and insight to the stakeholders' needs [36]. Yonkers [25] states that to protect through objective assurance and advice, an internal audit enables one to address emerging critical risks and provide relevant insight in a timely fashion to a company's stakeholders. Internal auditors have to employ highly efficient methods such as agile methodologies for conducting their audit responsibilities. The Agile approach is particularly, appropriate for complex audits that demand a competent team coupled with experienced auditors to follow shorter audit cycles and faster delivery of services to its clients and speedy information to stakeholders for their decision making and to remain competitive in the market. This approach leads to increased audit quality and thus greater business value to the organization. The adoption of an Agile methodology to internal audit is increasing due to technological disruptions and demand for a speedy and timely assurance on material issues. Since the Agile methods in internal audits are of great help, therefore, internal auditors should embrace this methodology to enhance their professional reputation and relevance. Additionally, the scaling for Agile internal auditing will widely differ from one company to another depending on the size, capabilities, and culture of the organization. Gupta, Kelkar, and Gupta [20] strongly support the adoption of this innovative methodology and state as follows: "Adopting the agile method provides ways of enhancing flexibility in audit planning, execution, and reporting. For such reasons as of today, 55 percent of internal audit groups are either using agile internal audit methods or are considering to adopt them".

Since agile internal auditing is based on a holistic mindset and team culture for its successful implementation, this implies that in Agile internal auditing, product development needs to be embedded into an Agile organization transformation [13]. 


\subsection{Future research}

Being an emerging and fast-growing subject, academics and researchers should also pave urgent attention to researching internal auditing practices in this area. Currently, there is a lack of adequate empirical output in the literature in this context. For example, researchers may be interested to explore in which types of organization (size), Agile internal audit may be more successful. For which types of organization, this approach works? Watson [37] recommends that future studies may be conducted by applying the combination of Scrum and Kanban models in practice if the companies are looking for improving efficiency and quality. Also, the experiences or perceptions of internal auditors from large and small organizations may be documented for the need of adopting Agile auditing. Similarly, how different agile methods such as Feature-Driven Development (FDD) and Extreme Programming (XP), may be used in audit processes to reduce audit cycle or productivity.

What type of organizational capabilities and culture Agile approach would need? How can companies adopt the agile approach in harmony with international standards for auditing Standards ((ISA)? Wilhelm [23] suggests that more Agile internal audit case studies to generate hypotheses based on cross-case analyses need to be conducted. Additionally, what could be a set of appropriate metrics which may be developed to measure the efficiency and effectiveness of the Agile internal audit projects. What could be behavioral implications of Agile internal audit approaches on team members, may also be investigated.

Last but not the least, Lehmann and Thor [18] in the context of new general internal audit, state that internal auditors need to deploy some of the levers, capabilities, and methodologies which are grouped into three main categories: governance, methodology, and enabling technology. Therefore, future research opportunities may be explored to internal auditors' capabilities and the use of auditing methodologies in improving the governance practices as well as how emerging technologies may influence the internal audit function in improving efficiency and effectiveness. We need to remember that today, Stakeholders are expecting more from the internal audit function (IAF) [38].

\section{Acknowledgment}

The author is very thankful to the two anonymous reviewers for their thought-provoking comments which helped in improving the quality of this paper. Thanks, are also due to the Editor for providing timely editorial comments on this paper.

\section{References}

[1] J. Kokina and T. H. Davenport, "The emergence of artificial intelligence: How automation is changing auditing," Journal of Emerging Technologies in Accounting, vol.14, no.1, pp.115-122, (2017)

[2] PWC, "Staying the course toward true north: Navigating disruption," (2017), Retrieved on 8 December 2020 from: https://www.pwc.com/us/en/risk-assurance/sotp/2017-state-of-the-internal-audit-professionreport.pdf.

[3] R. I. Newmark, G. Dickey, and W.E. Wilcox, "Agility in audit: Could scrum improve the audit process? Current issues in auditing," American Accounting Association, vol.12, (Spring) pp.18-28, (2018)

[4] L. Rowe, "Introducing agile into internal audit," Financial Management, (2019), Retrieved on 2 October 2020 from: https://www.fm-magazine.com/issues/2019/aug/agile-business-practice-implementation-internalaudit.html 
[5] Deloitte, "Becoming agile: A guide to elevating internal audit's performance and value," (2017), Retrieved on 1 October 2020 from: https://www2.deloitte.com/content/dam/Deloitte/us/Documents/finance/usadvisory-agile-internal-audit-part1-introduction-to-elevating-performance.pdf

[6] R. A. Wright Jr., "Agile auditing: Transforming the internal audit process," Institute of Internal Auditors (IIA), Malaysia, (2019)

[7] L. Berger, “Agile internal audit: How to audit at the speed of risk," (2020), Retrieved on 30 September 2020. https://blog.protiviti.com/2020/01/27/agile-internal-audit-how-to-audit-at-the-speed-of-risk/

[8] IIA, "2018 North American pulse of internal audit: Internal audit transformation is imperative," Institute of Internal Auditors, (2018), Retrieved on 2 October 2020 from: https://dl.theiia.org/AECPublic/2018-NAPulse-of-Internal-Audit-Report-NM.pdf

[9] ProofHub, "What are the 10 key characteristics of agile project management?" (2019), Retrieved on 28 March 2021 from: https://blog.proofhub.com/what-are-the-main-characteristics-of-an-agile-project-managementmethodology-e28c4bd59b55

[10] Deloitte, “Adopting agile," (2020), Retrieved on 7 March 2021 from: https://www2.deloitte.com/content/dam/Deloitte/us/Documents/finance/us-adopting-agile-pov.pdf

[11] J. B. Rajkumar, "How to deliver high-value software features in a short period using agile scrum process," (2021), Retrieved on 7 March 2021 from: https://www.softwaretestinghelp.com/how-to-deliver-high-valuesoftware-features-in-a-short-time-period-using-agile-scrum-process

[12] KPMG, "Agile internal audit: White paper on working agile within internal audit functions," (2019), Retrieved on 2 October 2020 from: https://assets.kpmg/content/dam/kpmg/cn/pdf/en/2020/06/agile-internalaudit-white-paper-on-working-agile-within-internal-audit-functions.pdf

[13] D. Beerbaum, “Application of agile audit: A case study research,” (2020), Retrieved on 7 March 2021 from: https://www.researchgate.net/publication/346652158

[14] J. Romano, “Agile auditing: Transforming internal audit to add greater value," (2019), Retrieved on 3 October 2020from: https://www.bakertilly.com/insights/the-agile-internal-audit-journey-series-part-i--transforminginternal-audit-to-add-greater-value

[15] J. Pagac and A. Roy, "Transforming internal audit methodology into agile IA," Webinar Series, (2019), Accessed on 3 October 2020. https://www.bdo.com/getattachment/Events/Transforming-Internal-AuditMethodology-into-Agile/Recording-and-Materials/2019-IAWebinar_Course5_Agile_FINAL_111919-

(1).pdf.aspx?lang=en-US

[16] Galvanize, "An overview of agile auditing," (2019), Retrieved on 3 October 2020 from: https://www.wegalvanize.com/audit/an-overview-of-agile-auditing/

[17] Deloitte, “Agile internal audit," (2019), Retrieved on 5 March 2021 from: https://chapters.theiia.org/ francisco/ChapterDocuments/IIA\%20Fall\%20Seminar\%202019-Agile_IA_Training_SF\%20IIA.pdf

[18] D. Lehmann and M. Thor, "The next generation of internal audit: Harnessing value from innovation and transformation," The CPA Journal, January, (2020)

[19] P. Alexiou, "Agile audit," ISACA Journal, (2017), Retrieved on 3 October 2020 from: https://www.isaca.org/resources/isaca-journal/issues/2017/volume-2/agile-audit

[20] A. Gupta, R. Kelkar, and A. S. Gupta, "Agile internal audit - The need for change in traditional IA methodology," The Chartered Accountants, India, pp.25-29, June, (2019)

[21] C. Blanding and M. Child, "Agile Auditing," (2019), Retrieved on 2 October 2020 from. https://chapters.theiia.org/topeka/Documents/Agile\%20Auditing\%20Topeka\%20IIA\%20100119.pdf

[22] D. D. Psy, "Is your audit agile enough? MISTI," Training Institute, (2020), Retrieved on 15 November 2020 from: https://webcache.googleusercontent.com/search?q=cache:-rjxYamd7lcJ:https://misti.com/resourceforms/blog-entry/internal-audit-insights/is-your-audit-agile-enough+\&cd=1\&hl=en\&ct=clnk\&gl=in

[23] P. Wilhelm, "Agile internal auditing - the case back to normal," 9th International Conference on Leadership, Technology, Innovation, and Business Management: Leadership, Innovation, Media and Communication, The European Proceedings of Social and Behavioral Sciences (EpSBS), (2019), Retrieved on 3 October 2020 
[24] Eu Consultancy, "Half of the companies applying agile methodologies and practices," (2020), Retrieved on 17 November 2020 from: https://www.consultancy.eu/news/4153/half-of-companies-applying-agilemethodologies-practices

[25] M. Yonkers, “An agile approach to internal auditing," (2018), Retrieved on 2 October 2020 from: https://www.isaca.org/resources/news-and-trends/isaca-now-blog/2018/an-agile-approach-to-internalauditing

[26] KPMG, “Agile internal audit. White paper on working agile within internal audit functions (Part II)”, (2020), Retrieved on 29 March 2021 from: https://assets.kpmg/content/dam/kpmg/nl/pdf/2020/sectoren/agileinternal-audit-2.pdf

[27] I. Hussain, “Applying agile principles to an internal audit," Misti Training Institute, (2019), Retrieved on 7 March 2021 from: https://misti.com/logout/blog-entry/internal-audit-insights/applying-agile-principles-tointernal-audit

[28] S. Agarwal, "What is Kanban in agile values, principles, benefits, and career," Knowledge Hut, (2019), Retrieved on 8 March 2021 from: https://www.knowledgehut.com/blog/agile/what-is-kanban-in-agilevalues-principles-benefits-career

[29] Deloitte, "Mind over matter: Implementing agile internal audit," The Wall Street Journal, (2018), Retrieved on 29 March 2021 from: https://deloitte.wsj.com/riskandcompliance/2018/08/06/mind-over-matterimplementing-agile-internal-audit/

[30] J. B. Connors, "Agile metrics: 4 balanced KPIs to measure success", (2020). Retrieved on 7 March 2021 from: https://appliedframeworks.com/agile-metrics-4-balanced-kpis-to-measure-success/

[31] A. Spencer and P. Wang, "Suncorp: Agile and internal audit," (2019), Retrieved on 14 November 2020 from: https://businessagility.institute/wp-content/uploads/2019/02/suncorp-agile-and-internal-audit.pdf

[32] Gartner, "Case study: Agile audit staffing, planning and project management (Aflac)," (2020), Retrieved on 29 March 2021 from: https://www.gartner.com/en/documents/3981884/case-study-agile-audit-staffingplanning-and-project-man

[33] E. Mkoba and C. Marnewick. "Conceptual framework for auditing agile projects," IEEE Access, vol.8, pp.126460-126476, (2020)

[34] L. Hogan, "Using scrums and sprints - Adopting agile for internal audit," (2018), Retrieved on 2 October 2020 from: https://www.iia.org.au/sf_docs/default-source/sopac-2018/presentations-etc/2a-using-scrumsand-sprints.pdf?sfvrsn=2

[35] S. McIntosh, "What exactly is the agile mindset?" (2016), Retrieved on 7 March 2021 from: https://www.infoq.com/articles/what-agile-mindset/

[36] N. Marks, "Why does internal audit need to be agile?" CMS Wire, (2020), Retrieved on 3 October 2020 from: https://www.cmswire.com/information-management/why-does-internal-audit-need-to-be-agile/

[37] C. Watson, "Agile auditing: Modernize your auditing practice," (2020), Retrieved on 29 March 2021 from: https://www.ideagen.com/thought-leadership/blog/agile-auditing-modernise-your-auditing-practice

[38] F. Osinubi, "The agile internal audit function: Stakeholders expect more from internal auditors," PWC, (2017) Retrieved on 2 October 2020 from: https://www.pwc.com/ng/en/assets/pdf/the-agile-internal-auditfunmtion.pdf 


\section{Author}

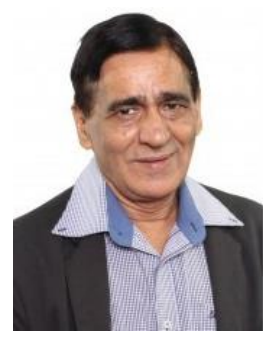

Dr. Prem Lal Joshi

Former Professor of Accounting at MMU Malaysia and University of Bahrain 
A Review of Agile Internal Auditing: Retrospective and Prospective

This page is empty by intention. 